\title{
A Study of Predictive Factors Affecting Health: Promoting Behaviors of North Korean Adolescent Refugees
}

\author{
Jin-Won Noh' ${ }^{1}$, Hyo-Young Yun ${ }^{2}$, Hyunchun Park ${ }^{3}$, Shi-Eun Yü* \\ ${ }^{1}$ Department of Healthcare Management and Institute of Global Healthcare Research, Eulji University, Seongnam; ${ }^{2}$ Department of Korean \\ Unification Studies, Yonsei University, Seoul; ${ }^{3}$ Department of Healthcare Management, Eulji University, Seongnam; ${ }^{4}$ Department of North Korea \\ Studies, Korea University, Sejong, Korea
}

Objectives: The present study aimed to analyze the factors that could affect the health-promoting behaviors of North Korean adolescent refugees residing in South Korea.

Methods: Questions about their sociodemographic variables, subjective health status, healthy living habits, and health-promoting behaviors were asked.

Results: Statistically significant differences were found in religion $(t=2.30, p<0.05)$, having family members in South Korea $(t=2.02$, $p<0.05)$, and subjective health status $(t=4.96, p<0.01)$. Scores on health-responsible behaviors were higher with higher age $(t=2.90$, $p<0.01)$ and for subjects without family or friends $(t=2.43, p<0.05)$. Higher physical-activity behaviors were observed in males $(t=3.32, p<0.01)$, in those with better subjective health status $(t=3.46, p<0.05)$ and lower body $\operatorname{mas}$ index $(t=3.48, p<0.05)$, and in smokers $(t=3.17, p<0.01)$. Nutritional behaviors were higher in those who followed a religion $(t=2.17, p<0.05)$. Spiritual growth behaviors were higher in those who followed a religion $(t=4.21, p<0.001)$, had no family in South Korea $(t=2.04, p<0.05)$, and had higher subjective health status $(t=5.74, p<0.01)$. Scores on interpersonal relationships and stress-management behaviors were higher for those with higher subjective health status. A multiple regression analysis showed greater effects on health-promoting behaviors when subjective health status was better. Older people and non-smokers exhibited more health-responsible behaviors, while more physical-activity behaviors and spiritual growth activities were observed when subjective health status was better. Interpersonal relationship behaviors had positive effects on those with good subjective heath status and on non-smokers.

Conclusions: Based on the results of the current study, an alternative was suggested for promoting health in North Korean adolescent refugees.

Key words: Democratic People's Republic of Korea, Refugees, Adolescent, Health promotion

Received: October 21, 2014 Accepted: July 22, 2015

Corresponding author: Shi-Eun Yu, PhD

2511 Sejong-ro, Sejong 30019, Korea

Tel: +82-44-860-1276, Fax: +82-44-860-1278

E-mail: seyou1224@hanmail.net

${ }^{*}$ Current affiliation: Clinical Trial Center, Korea University Medical Center, Seoul, Korea

This is an Open Access article distributed under the terms of the Creative Commons Attribution Non-Commercial License (http://creativecommons.org/licenses/by$\mathrm{nc} / 3.0 /$ ) which permits unrestricted non-commercial use, distribution, and reproduction in any medium, provided the original work is properly cited.

\section{INTRODUCTION}

By the June of 2015, 28133 North Korean refugees had entered South Korea. As the number of North Korean female refugees sharply increased since 2002, the entry of family units and adolescents increased [1]. Among those entrants, 1055 (3.8\% of all entrants) were adolescents over 14 years old and less than 24 years old who attend middle school and high school [2]. Health gave positive influence on the adjustment 
of these North Korean refugees to the new South Korean society, and became the foundation for the North Korean adolescent refugees' education and adaptation $[3,4]$.

Generally, the concept of health is used in contrast with that of disease. Health can be defined as a relative concept that is formed by interactions between personal perceptions and sociocultural factors, rather than by an absolute reference $[5,6]$. In addition, health is essential for a person to maintain physical independence, functionally live daily life, and carrying out one's social role or accomplish social integration [7]. In a broad sense, health behavior can be defined as a variety of behaviors of people, to maintain, promote, and recover health. The World Health Organization emphasized changing from a passive attitude in which health is considered as the state of no disease, to an active one that involves changing lifestyles, through efforts like exercising to become healthy [8]. In addition, eating habits for promoting health, physical-activity behaviors, and health are considered as wellness [9]. Therefore, lifestyle diseases can be prevented with appropriate health behaviors during adolescence, when habits are being formed. In addition, the appropriate health habits formed during adolescence will continue even after entering adulthood, such that it will have positive influences not only on individuals, but also on families and local communities.

Until now, no empirical studies have examined the health of North Korean adolescent refugees who experienced starvation in North Korea. Research related to the health of North Korean adolescent refugees mostly includes qualitative studies on nutritional status and health risk factors in North Korea. Yoon [10] stated that malnutrition in North Korea and physical and mental trauma from the long-term tense living during the escape from North Korea caused illness in North Korean adolescent refugees after they entered South Korea. Jeon and Park [11] identified North Korean adolescent refugees' experiences of folk remedies in North Korea, repatriation to North Korea, and prolonged stay in a third country as health risk factors. Yoon [3], who studied the health and economic adaptations of North Korean refugees, said that health is the most significant factor preventing these refugees from employment. Kim and $\mathrm{Yu}$ [12] reported that the subjective health of North Korean refugees is about five times worse than that of South Koreans. In addition, illnesses that North Korean refugees were either suffering from or being treated for were 3.8 times higher than that of South Koreans in general, and 1.4 times higher than that of those from the low-income group. That is, North Kore- an refugees had relatively more bodily and chronic illnesses as compared to South Koreans [12]. Kang et al. [13] studied the health-promoting lifestyle of North Korean refugees and revealed an average score of $1.78 \pm 0.35$ (out of 4 points). This score was significantly lower as compared to those of immigrants or health vulnerability groups using the same instrument. In other words, North Korean refugees' score on the Health-Promoting Lifestyle Profile (HPLP) was relatively low as compared to those of unmarried adolescent Canadian mothers (2.8 \pm 0.39$)$ [14] and Brazilian immigrants in the US (2.53 \pm $0.46)$ [15].

The studies discussed above suggest the seriousness of health problems of North Korean adolescent refugees, and it appears to be an important influential factor affecting their new life. In other words, it suggests that an empirical study is needed to improve the health, which is a human capital, of North Korean adolescent refugees settled in South Korea, where the social and cultural systems are different. Such health studies on North Korean adolescent refugees have significance not only in promoting the health of North Korean adolescent refugees but also in finding solutions for the health disparities between the people of South and North Korea after unification.

Accordingly, the present study attempted to examine the subjective health status, healthy living habits, and health-promoting behaviors of North Korean adolescent refugees living in South Korea, and to identify the factors that affect their healthpromoting behaviors. Based on the results, an alternative to improve the health-promoting behaviors of North Korean adolescent refugees has been suggested.

\section{METHODS}

\section{Subjects}

The present study was carried out from December 11, 2013 to February 26,2014 , with cooperation from an educational institution for North Korean adolescent refugees. The subjects were 150 North Korean adolescent refugees living in South Korea, who are over 14 years old and less than 24 years old. The age of the subjects was limited to 24 years was because it corresponded to the school age described in the Elementary and Secondary Education Act, under the provision of Article 45, paragraph 2 of the North Korean Refugees Protection and Settlement Support Act.

The research team carried out convenience sampling that focused on alternative schools for North Korean adolescent 
refugees, local Hana Centers, and communities. Out of the 150 questionnaires distributed, 123 copies were included in the final analysis, after excluding missing or insincere answers.

\section{Instruments}

Sociodemographic variables, subjective health status, healthy living habits, and health-promoting behavior were examined in the present study.

The sociodemographic variables included sex, age, current grade, religion, location of residence, status of receiving the National Basic Living Security, duration of stay in South Korea, and presence of family members in South and North Korea.

Subjective health status was assessed on a five-point scale by asking, "What do you think about your health?"

Healthy living habits were assessed using the body mass index (BMI), and smoking and drinking habits. BMI was categorized as follows: underweight $=18.5$ or less, normal $=23$ or less, overweight $=25$ or less, and obese $=25$ or more. Smoking was categorized as "currently smoking" and "currently not smoking." Similarly, drinking was classified as "currently drinking" and "currently not drinking."

To assess health-promoting lifestyle, the HPLP-II developed by Walker et al. [16] and translated by Yun and Kim [17] was used. It is composed of 52 questions, including 9 questions on health responsibility, 8 on physical activity, 9 on nutrition, 9 on interpersonal interactions, 9 on spiritual growth, and 8 on stress management. A higher average score is indicative of higher degree of implementation of health-promoting behaviors. In Walker et al.'s study [16] the Cronbach's $\alpha$ of the tool was 0.94, while the same in Yun and Kim's study [17] was 0.93. In the present study, its Cronbach's $\alpha$ was 0.799 .

The current study was approved by the institutional review board of Eulji University (EU 13-36).

\section{Statistical Analysis}

The data were analyzed using SPSS version 21.0 (IBM Corp., Armonk, NY, USA). First, frequencies and percentages on the sociodemographic characteristics, subjective health status, and healthy living habits of North Korean adolescent refugees were computed. Subsequently, the means and standard deviations on the health-promoting behaviors were calculated. Sociodemographic characteristics, subjective health status, and healthpromoting behaviors according to lifestyle were then analyzed using the $t$-test and one-way ANOVA. To check for multicollinearity, variance inflation factors (VIF) were calculated, and the Shapiro-Wilk's test was performed to check for normal distribution of the dependent variables. It was found that all the VIF values were less than 10 , which indicates that there was no problem of multicollinearity. Additionally, the $p$-values of the Shapiro-Wilk's tests were all 0.05 or greater, which indicates that all dependent variables were normally distributed. Lastly, a multiple regression analysis was performed to identify the factors that affect the subjects' health-promoting behaviors.

\section{RESULTS}

The average score on health-promoting behaviors was 2.51 . Further, the averages of the six sub-scales were as follows: the average score on interpersonal relationship behaviors was the highest (2.87), followed by spiritual growth behaviors (2.80), nutritional behaviors (2.45), stress-management behaviors (2.41), physical-activity behaviors (2.28), and health-responsible behavior (2.21) (Table 1).

On comparing health-promoting behaviors according to the characteristics of the North Korean adolescent refugees, we found that religion, absence of family in South Korea, and subjective health status affected the health-promoting behaviors. In other words, the score on health-promoting behaviors was significantly higher when the subject followed a religion, had no family in South Korea, and had better subjective heath status. Further, the health-responsible behavior score was significantly higher when the subject's age was higher and when his/ her family was not in South Korea. Significantly higher physical-activity behaviors were observed in males, in those with better subjective health status and lower BMI, and in smokers. Nutrition behaviors were significantly better when the subject had a religion. Further, the score on spiritual growth behaviors was higher when the subject had a religion, had no family in South Korea, and had better subjective health status. Similarly,

Table 1. Mean scores on the health-promoting behaviors of North Korean adolescent refugees

\begin{tabular}{llc}
\hline Characteristics & \multicolumn{1}{c}{ Categories } & Mean \pm SD \\
\hline Health-promoting behavior & Overall & $2.51 \pm 0.32$ \\
& Health responsibility & $2.21 \pm 0.41$ \\
& Physical activities & $2.28 \pm 0.55$ \\
& Nutrition & $2.45 \pm 0.39$ \\
& Spiritual growth & $2.80 \pm 0.50$ \\
& Interpersonal relationship & $2.87 \pm 0.43$ \\
& Stress management & $2.41 \pm 0.41$ \\
\hline
\end{tabular}

SD, standard deviation. 
interpersonal relationship behaviors and stress-management behaviors were significantly higher when subjective health status was better (Table 2).

A multiple regression analysis was performed to identify the variables that affect health-promoting behaviors of North Korean adolescent refugees.

When we examined the factors that affected the overall health promoting behavior score and the scores on the six subscales, we found that the subjective health status of subjects influenced their health-promoting behavior. That is, the better the subject health status, the higher the health promoting behavior score. With reference to health-responsible behavior, the higher the age was, and when the subject was a non-smoker, the more they tended to indulge in health-responsible behavior. Subjects showed more physical-activity behaviors when their subjective health status was better, and showed more spiritual growth behaviors when they had a religion, and their subjective health status was better. Finally, their interpersonal relationship behaviors were better when they had a good subjective health status and when they were non-smokers (Table 3).

\section{DISCUSSION}

The purpose of the current study was to present empirical data for North Korean adolescent refugees to live healthier lives by analyzing the factors that affect their health-promoting behaviors.

When the results of the current study were compared to those of previous studies that used the same instrument (HPLPII) on North Korean adult refugees, the health-promoting behaviors of North Korean adolescent refugees can be positively evaluated because their average score and all sub-scale scores were higher. Comparing the average health-promoting behaviors score of $1.78 \pm 0.35$ revealed in the study by Kang et al. [13] and $2.38 \pm 0.57$ revealed in the study by Choe et al. [18], where both studies used North Korean adult refugees as subjects, we found that the health-promoting behaviors of North Korean adolescent refugees $(2.51 \pm 0.32)$ were better than those of the adults. Meanwhile, the health-promoting behaviors of North Korean adolescent refugees were similar to the average score of South Korean high school students (2.49 \pm 0.39$)$ [19]. However, with reference to health-promoting behaviors, the proportion of North Korean adolescent refugees who skipped breakfast was higher than that of South Korean adolescents [20]. Based on the results of the current study, following sug- gestions were made to promote the health of North Korean adolescent refugees.

First, a social support network should be promoted for these adolescents. Specifically, we found that North Korean adolescent refugees who did not have a family in South Korea showed higher health-responsible behaviors than those who had a family in South Korea. This may indicate that they are managing their health better with the hope of meeting their families in North Korea. On one hand, even though they lack of blood relatives who would support their health environmentally, they may be receiving more private and public support because they comprise the vulnerable class for the social support network. North Korean adolescent refugees without a family or friends are placed in alternative boarding schools, specialized schools, group homes, and shelters until they become a 20 -year-old adult, after which, they are provided a rental house. In addition to basic provisions such as medical and educational protection according to the Act on Protection and Settlement Support of Residents Escaping from North Korea, they receive educational benefits such as after-school learning from Korea Hana Foundation and other related organizations $[21,22]$. Therefore, if multifaceted support is possible for North Korean adolescent refugees through support from the family as well as the improved social support network, it will positively influence the promotion of their health.

Second, the health-promoting behaviors of the North Korean adolescent refugees should lay a balanced emphasis on mental health. It was found that activities related to interpersonal relationships and spiritual growth of the subjects were more vigorous than their physical-activity behaviors. In addition, those living religious lives were more actively involved in health-promoting behaviors than those who did not. This means that the Juche Ideology, which is similar to religion, had been socialized and internalized as a spiritual value. In other words, as the North Korean adolescent refugees may feel that they betrayed their country and "escaped" and settled in the enemy country, South Korea, religion is carrying out a role in forming a new sense of belonging and achieving psychological stability. In addition, as they develop new relationships in South Korea, a need for the sense of social belonging and support network arises. Indeed, religion has an important function in overcoming the uncertainty and pursuing values in the lives of North Korean adolescent refugees [23]. In a study on North Korean refugees by Jeon and Cho [24], they stated that a religious life could help them gain peace of mind, find direc- 


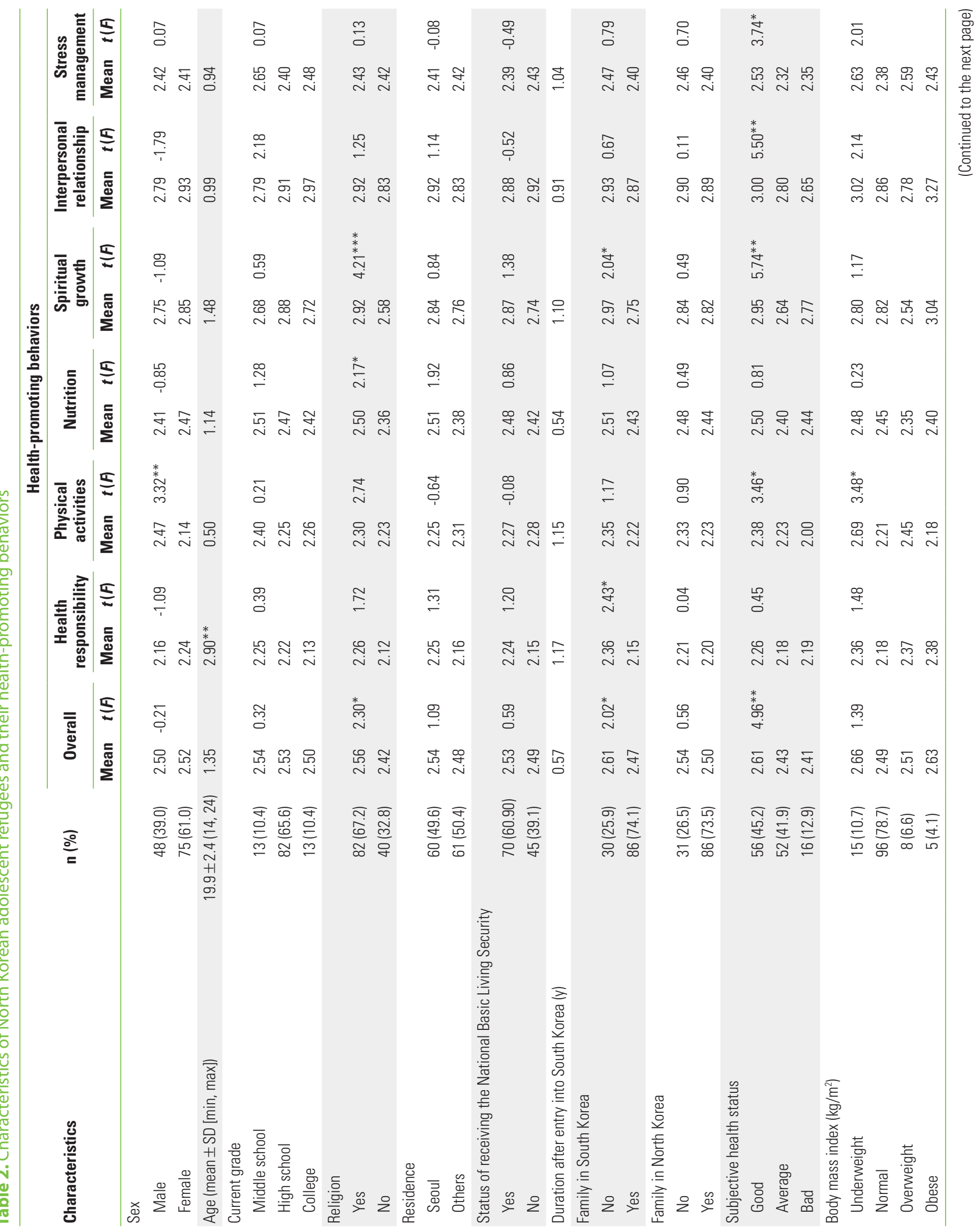



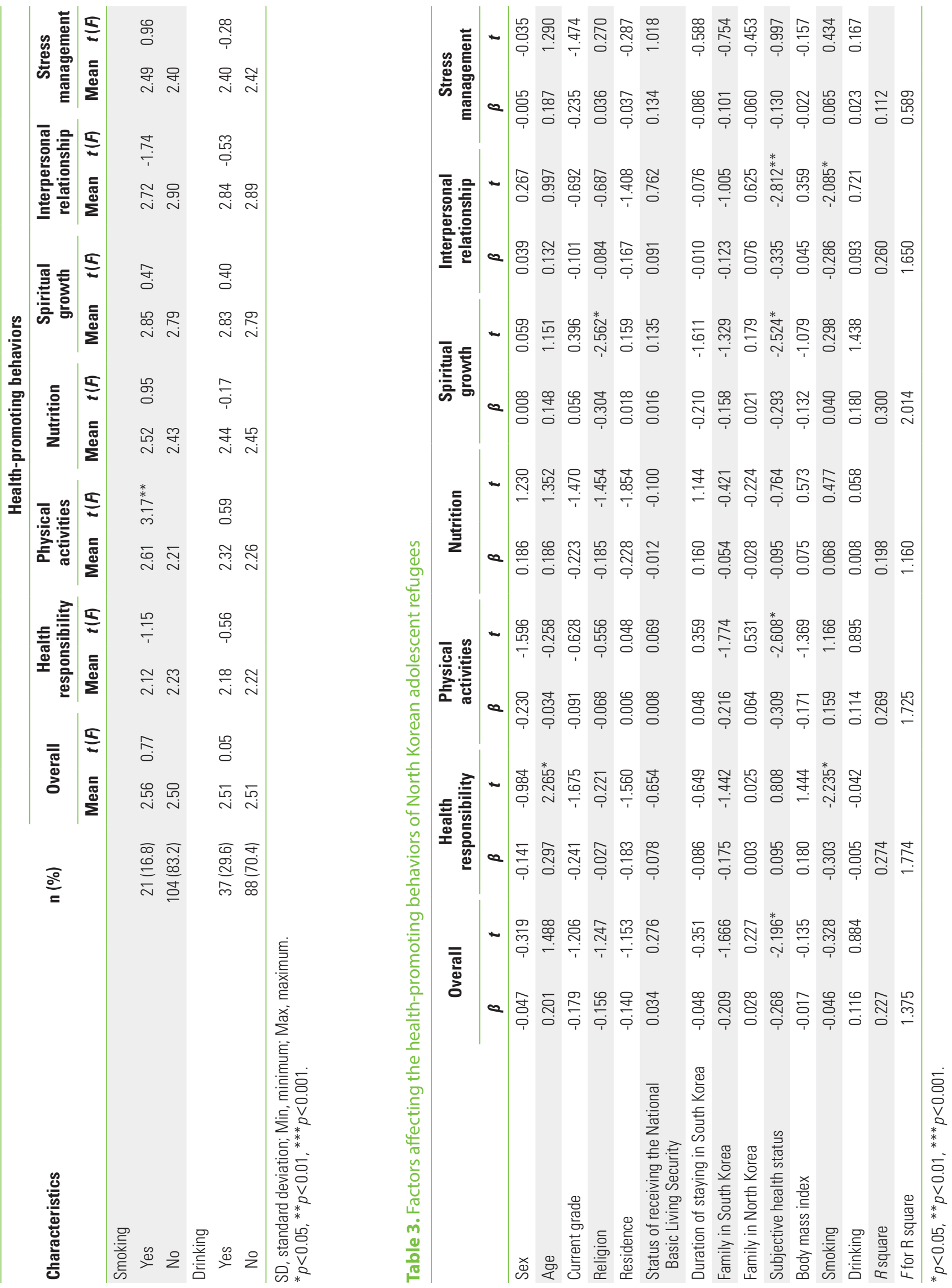
tion and values of life, and make friends. Therefore, it appears that a religious life is closely related to the promotion of health. Thus, the spiritual life of North Korean adolescent refugees could help them pursue a healthy life by providing psychological stability and positive power in daily life.

Third, education and programs should be conducted to facilitate the health-promoting behaviors of North Korean adolescent refugees. Such refugees have lived an unstable and irregular life, which requires constant moving for survival during their stay in North Korea and other countries. That is, after experiencing food shortage, as the education system collapses, they had to wander around to find a market or food rather than continuing their studies. For the North Korean adolescent refugees who lived such lives, the competitive educational environment in South Korea would lead to psychological pressure and physical lethargy. Accordingly, as a means to promote psychological and physical health and to support the adjustment of the North Korean adolescent refugees, practical programs that are fun to participate should be provided. Such programs will not only provide them an opportunity to promote physical health but also to support mental health by avoiding depression and fostering interpersonal relationships. This is supported by previous studies [25-27] which shows that a moderate level of physical-activity behaviors through exercise programs positively affects adolescents'subjective health status. Therefore, it is necessary to develop programs and continuous recommendations to facilitate active and aggressive participation of North Korean adolescent refugees in physical-activity behaviors not only in school, but also during leisure activities.

Lastly, education on a regular and balanced diet should be provided. North Korean adolescent refugees did not have an opportunity to experience regular and balanced diet during their stay in North Korea and other countries. According to Hwang and Chang [28], 74\% of their subjects had regular meals without skipping the same while they were living in North Korea, but they used substitute food to fulfill the lack of food intake. Kim and Jeong [29] stated that the lower the age of the North Korean refugees, the more they preferred salty taste and white rice than multi-grain, and frequently consumed noodles. In addition, they preferred the North Korean diet culture to South Korean eating habits or food supplies. Such results indicate that irregular and unbalanced diet of North Korean refugees may lead to chronic malnutrition. Accordingly, by specifically educating them about regular and balanced diet, their health could be improved. For example, it is necessary to educate and provide information to North Korean refugee families about the 10 healthy life indicators for Koreans advocated by the Korea Health Promotion Foundation. In particular, due to the differences in diet between South and North Korea, it is important to provide informational support for healthy living by conducting education on a balanced diet.

The health-promoting behavior of North Korean adolescent refugees is the foundation for adjusting to the new society of South Korea. Therefore, promotion of and prescription for bodily health should be done well before adulthood, that is, since childhood and adolescence. In case of North Korean adolescent refugees, since not many of them attend regular South Korean schools, the health-promoting education should be conducted not only at schools but also through Hanawon, Hana Centers, and local social welfare organizations. In particular, preventive education on diseases is necessary, and specific programs that can focus on health-promoting behaviors related to the growth during adolescence should be provided. Findings of this study on the health of North Korean adolescent refugees will be utilized as a model to resolve the health differences between South and North Korean adolescents and to promote the health of North Korean adolescents.

\section{ACKNOWLEDGEMENTS}

This study was supported by the Intramural Research Support of Eulji University, 2013.

\section{CONFLICT OF INTEREST}

The authors have no conflicts of interest with the material presented in this paper.

\section{REFERENCES}

1. Ministry of Unification. Number of North Korean refugees entered the South Korea [cited 2015 Sep 5]. Available from: http://www.unikorea.go.kr/content.do?cmsid=1440 (Korean).

2. Ministry of Education. The press on the plan for North Korean students' education support 2015; 2015 Mar 5 [cited 2015 Mar 5]. Available from: http://www.moe.go.kr/web/100026/ko/ board/view.do?bbsid $=294 \&$ pageSize $=10 \&$ currentPage $=0 \& \mathrm{e}$ $n$ code $\mathrm{n}=\mathrm{N} \&$ boardSeq $=58634$ \&mode $=$ view (Korean).

3. Yoon IJ. Relationships between health and economic adaptation of North Korean migrants. Health Soc Sci 2007;21(1):65- 
96 (Korean).

4. Kim HJ. Stress coping strategies of North Korean refugee adolescents in South Korea according to attribution style and defense style [dissertation]. Seoul: Seoul National University; 2013 (Korean).

5. Kang HS, Lee H, Kim MW. The correlates of influenza vaccination among Korean elderly men and women. J Korean Acad Community Health Nurs 2011;22(1):45-55 (Korean).

6. Moon CJ. Sociology of health and medicine. Seoul: Shinkwang; 1990, p. 36-52 (Korean).

7. Lee KJ, Park HS. A study on the perceived health status, depression, and activities of daily living for the elderly in urban areas. Korean J Women Health Nurs 2006;12(3):221-230 (Korean).

8. National Youth Policy Institute. Korean survey on the health of youth and children in 2010. Sejong: National Youth Policy Institute; 2011, p. 23-36 (Korean).

9. So SS, Kim HK, Kim CS. Comparative study of gender and school grade differences in adolescent health. Korean J Youth Stud 2011;18(10):317-340 (Korean).

10. Yoon IJ. North Korean defector. Seoul: Jipmoondang; 2009, p. 227-241 (Korean).

11. Jeon JH, Park Y. The effects of individual characteristics and health beliefs on North Korean refugees' health behavior. J Korean Acad Community Health Nurs 2012;23(1):82-90 (Korean).

12. Kim BC, Yu SE. North Korean defectors panel study: economic adaptation mental health physical health. Seoul: North Korean Refugees Foundation; 2010, p. 68-94 (Korean).

13. Kang Y, Ha Y, Eun Y. Health status and Health-Promoting Lifestyle Profile II of North Korean immigrants. J Korean Acad Community Health Nurs 2012;23(3):231-243 (Korean).

14. Black C, Ford-Gilboe M. Adolescent mothers: resilience, family health work and health-promoting practices. J Adv Nurs 2004; 48(4):351-360.

15. Tajik M, Galvão HM, Eduardo Siqueira C. Health survey instrument development through a community-based participatory research approach: Health Promoting Lifestyle Profile (HPLP-II) and Brazilian immigrants in Greater Boston. J Immigr Minor Health 2010;12(3):390-397.

16. Walker SN, Sechrist KR, Pender NJ. The Health-Promoting Lifestyle Profile: development and psychometric characteristics.
Nurs Res 1987;36(2):76-81.

17. Yun SN, Kim JH. Health-promoting behaviors of the women workers at the manufacturing industry: based on the Pender's health promotion model. Korean J Occup Health Nurs 1999; 8(2):130-140 (Korean).

18. Choe MA, Yi M, Choi JA, Shin G. Health Knowledge, Health promoting behavior and factors influencing health promoting behavior of North Korean defectors in South Korea. J Korean Acad Nurs 2012;42(5):622-631 (Korean).

19. Kim MS, Kang HS, Cho KJ. Factors Influencing health-promotion behavior in adolescents. Korean J Child Health Nurs 2004; 10(4):496-503 (Korean).

20. Korea Hana Foundation. The survey of North Korean youth refugees. Seoul: Korea Hana Foundation; 2015, p. 252-308 (Korean).

21. Kim HK. A qualitative study on the changing expectation of orphans coming from North Korea in South Korea. J Future Oriented Youth Soc 2013;10(2):69-101 (Korean).

22. Kim HA, Bang KY. The experiences of workers at group homes for North Korean youth defectors. Stud Korean Youth 2012; 23(3):137-170 (Korean).

23. Kim DG. Religion psychology. Seoul: Hakgisa; 2003, p. 155-218 (Korean).

24. Jeon WT, Cho YA. Religious experiences of North Korean defectors in South Korea and the role of churches for the Korean unification. Korean Unification Stud 2003;7(2):105-128 (Korean).

25. Lee BS, Kim JS, Kim KS. Factors that affect the subjective health status of adolescents in multicultural families. J Korean Public Health Nurs 2013;27(1):64-75 (Korean).

26. Kwon HJ, Cho KO, Oh JW, Lee O, Kim YS. Association between levels of physical activity and self-rated health in Korean adolescents: the 2009 Korea Youth Risk Behavior Web-based Survey. Korean J Phys Educ 2012;51(5):253-261 (Korean).

27. Mun YH. The state and factors associated with the level of physical activity and exercise in adolescents. J Korean Public Health Nurs 2007; 21(1):75-84 (Korean).

28. Hwang JY, Chang NS. Dietary patterns and nutrient intake in North Koreans by utilizing literature search and survey. Korean J Community Nutr 2001;6(3):371-379 (Korean).

29. Kim MJ, Jeong HS. Study on dietary habits of North Korean refugees. J East Asian Soc Diet Life 2011;21(1):1-13 (Korean). 